\title{
Genetic and environmental contributions to variations on appetitive traits at 10 years of age: a twin study within the Generation XXI birth cohort
}

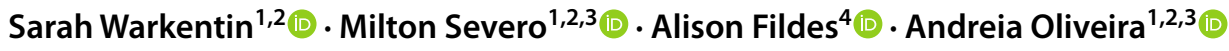

Received: 28 May 2021 / Accepted: 13 October 2021 / Published online: 6 November 2021

(c) The Author(s) 2021

\begin{abstract}
Purpose Given the variability in adiposity despite ubiquitous exposure to obesogenic food environments, it has been suggested that individuals respond in divergent ways to the environment they live in. The food environment becomes more 'permissive' as children age; therefore, genetic predisposition for a more avid appetite can be better expressed, influencing dietary quality, energy intake and weight gain. Our aim was to explore the genetic and environmental contribution of variations on appetitive traits in a sample of 10 -year-old Portuguese children.

Methods Participants were twins enrolled in the Generation XXI birth cohort ( $n=86$ pairs). Parents reported twin's zygosity and child appetitive traits at 10 years of age through the Children's Eating Behavior Questionnaire. Intra-class correlations (ICCs) for all appetitive traits were calculated for monozygotic and dizygotic twins separately to examine patterns of resemblance, and structural equation modeling was conducted aiming to estimate the genetic $(A)$, shared $(C)$ and non-shared $(E)$ environmental variances.

Results Moderate to strong heritability were found for child appetitive traits, with higher ICCs among monozygotic twin pairs. For all appetitive traits, with the exception of emotional undereating, genetic and non-shared environmental effects contributed to appetite variability. For emotional undereating, environmental effects seem to be more important than genetic effects $(C: 0.81 ; 95 \%$ CI $0.71 ; 0.88$ and $E: 0.19 ; 95 \%$ CI $0.12 ; 0.29)$.

Conclusion There was a significant genetic contribution, followed by non-shared environmental contribution, towards variation in appetitive traits in school-age children. Variation in emotional undereating was primarily explained by shared and non-shared environmental factors.
\end{abstract}

Level of evidence Evidence obtained from well-designed cohort or case-control analytic studies.

Keywords Twins $\cdot$ Children $\cdot$ Feeding behaviors $\cdot$ Appetite $\cdot$ Heritability $\cdot$ Cohort studies

Sarah Warkentin

sarah.warkentin@ispup.up.pt

1 EPIUnit, Institute of Public Health, University of Porto, Rua das Taipas, 135-139, 4050-600 Porto, Portugal

2 Laboratory for Integrative and Translational Research in Population Health (ITR), Porto, Portugal

3 Department of Public Health and Forensic Sciences and Medical Education, Faculty of Medicine, University of Porto, Porto, Portugal

4 School of Psychology, University of Leeds, Leeds LS2 9JT, England

\section{Introduction}

Genetic and environmental factors interact in many complex ways in the development of childhood obesity [1]. Given the great individual variability in adiposity, and the increasing exposure to modern day obesogenic food environments over time, it is believed that individuals respond in divergent ways to the (food) environment that they live in, i.e., genetic predispositions to being overweight seem to be enhanced in higher risk home environments in preschoolers [2] and tend to increase from early childhood to school-age years [3] until late adolescence [4], reflecting the greater external exposure to obesogenic food environments [5], which can be defined as a genotype-environment interaction [6]. A large international study with over 12,000 twin pairs, reported 
that heritability of body mass index (BMI) increased substantially from approximately $8 \%$ at birth, to at least $50 \%$ at 5 years and around $75 \%$ in middle-childhood (7-9 years of age). In contrast, common environmental influences, i.e., those shared by twins in the same family, were higher at birth (approximately 75\%) and markedly reduced over time (9.6\% at 8 years and $0 \%$ at 16 years) [7]. Increases in BMI heritability were also described in another large study with data from 45 cohorts across the world, in which genes accounted for approximately $41 \%$ in BMI variability at 4 years and increased to $75 \%$ at 19 years, in both sexes. On the other hand, a strong influence of common environmental factors was observed in middle-childhood and disappeared after 15 years of age [8].

The gene-environment interplay in the development of obesity led researchers to the behavioral susceptibility theory (BST) of obesity [9], which proposes that genetic risk operates through inherited appetitive traits that confer individual's differential susceptibility to the food environment [5]. BST proposes a gene-environment interaction in which individuals with greater obesogenic appetitive traits, such as higher food responsiveness and lower satiety responsiveness, are more likely to overeat in situations when high palatable foods are available [5, 9]. This idea has been supported by twin studies, which have shown substantial genetic influence on potentially obesogenic appetitive traits in children, such as food responsiveness and enjoyment of food [10], eating rate [11] and eating in the absence of hunger [12], with modest effects of shared and non-shared environment. Genes seem to explain somewhere between 46 and $74 \%$ of child appetitive traits (such as slowness in eating, satiety responsiveness [13] and food fussiness [14]) in infants and toddlers, $72-78 \%$ of food fussiness [15] and food neophobia [16] in preschool- and $\sim 63-75 \%$ of satiety responsiveness/ slowness in eating and enjoyment of food [10] in schoolage years, also indicating an important genetic contribution in appetite variability across childhood. In contrast, other appetitive traits, such as emotional over- and undereating, seem to be less explained by genes, as shown in a study with 5-year-old twins, in which environmental cues seemed to strongly contribute to the variation of these traits [17].

When the child ages, parental influence tends to decrease and children gain autonomy concerning their food choices. Therefore, genetic predisposition for a more avid appetite can be better expressed, increasing the power for both genetic and environmental factors to influence energy intake and ultimately weight gain [5]. In accordance with the heritability estimates for BMI, as children age and gain autonomy, you may also expect increases in the genetic contribution to certain appetitive traits [17]. However, a longitudinal study in Canada suggested that, as children age, genetic influences on appetitive traits tend to decrease [18]. It is also worth mentioning that eating behaviors are also influenced by the cultural background, which plays a role on what is eaten, when, how much and with whom [19]. Further twin studies are, therefore, necessary to better comprehend genetic and environmental contributions to a range of appetitive traits at different stages of childhood, and also from different cultural backgrounds.

The majority of twin studies assessing genetic and environmental variability in child appetitive traits are from the UK $[10,11,14,17]$ and a limited number of studies have included children in school-aged years [10, 11]. To expand on previous findings in an older age-group, aiming to test if heritability of appetitive traits increases with child autonomy, in a different culture, with different eating environments, we aimed to explore genetic and environmental contributions to variation in appetitive traits among 10-year-old children from a Portuguese population-based birth cohort. In line with previous studies, we predicted that (i) appetitive traits in 10-year-old children would be highly heritable and (ii) environmental factors may be important underlying factors in child's emotional eating.

\section{Materials and methods}

\section{Study population}

Participants were children enrolled in the Generation XXI birth cohort. Recruitment took place between April 2005 and August 2006, in all public maternities of the metropolitan area of Porto (northern Portugal). Demographic and socioeconomic characteristics, obstetric history and previous personal diseases were collected in the maternity, within $72 \mathrm{~h}$ after delivery, in face-to-face interviews performed by trained interviewers and from clinical records [20, 21]. After the initial evaluation at birth (8647 children and 8495 mothers), follow-ups were conducted when children were $4(2009 / 2011)$ (86\% of participation proportion), 7 (2012/2014) (80\% of participation proportion) and 10 years of age (2015/2017) (76\% of participation proportion). From the 8647 children enrolled at baseline, the current study included only twin pairs $(n=288)$. Children with no information about zygosity $(n=36)$ and without data on eating behaviors at 10 years $(n=80)$ were excluded, resulting in a final sample of 172 children ( 86 twin pairs).

\section{Measures}

Zygosity was assessed through a nine-item questionnaire [22]. This questionnaire was completed by the mothers, and assessed their opinions about children's zygosity (e.g., "Do you think your twins are identical (monozygotic)?"), global similarity and twin confusion (e.g., "Are the children as alike as two peas in a pod?") and specific similarity (e.g., "Are 
there differences in your twins' eye colors?"). In addition, zygosity assessment was also performed by an independent observer, which classified the children as monozygotic (MZ), dizygotic (DZ) or unknown. A score of one point was given for each answer indicating similarity for a trait between twins and one point was subtracted for each answer indicating dissimilarity. A final score lower than 0 corresponded to DZ twins and scores equal to or above 0 corresponded to MZ twins. This questionnaire is a non-invasive tool of zygosity assessment and showed, previously, a high degree of accuracy (95.4\%) [22].

Eating behaviors at 10 years were assessed through a widely used parent-report questionnaire, namely the Children's Eating Behavior Questionnaire (CEBQ) [23] which was previously validated among the Generation XXI schoolaged children [24]. This questionnaire also showed good internal consistency at 10 years (Cronbach's $\alpha$ coefficients ranging from 0.76 to 0.84 [25]). Parents or main caregivers were asked to respond to the 35-item questionnaire, which assesses eight subscales: satiety responsiveness (CEBQSR-5 items, e.g., "My child leaves food on his/her plate at the end of a meal"), slowness in eating (CEBQ-SE—4 items, e.g., "My child eats slowly"), food fussiness (CEBQ-FF-6 items, e.g., "My child is difficult to please with meals"), emotional undereating (CEBQ-EUE—4 items, e.g., "My child eats less when s/he is upset") assess child's avoidance and lack of interest towards foods and will, therefore, be further called "food avoidant behaviors"; food responsiveness (CEBQ-FR - 5 items, e.g., "If allowed to, my child would eat too much"), enjoyment of food (CEBQ-EF-4 items, e.g., "My child loves food"), desire to drink (CEBQDD-3 items, e.g., "My child is always asking for a drink") and emotional overeating (CEBQ-EOE-4 items, e.g., "My child eats more when annoyed") assess child's general appetite and interest for food and drinks and will, therefore, be called "food approach behaviors". Answers were given using a 5-point Likert scale, ranging from 1-"Never" to 5-"Always", such that the higher the score, the more frequent the eating behavior. In accordance with the original scale, five of the items were reverse-scored. For questionnaires that were missing $<50 \%$ of data items (approximately $3 \%$ of the sample), subscale scores were calculated by replacing missing items with the mean of the items available. Adequate internal consistency was also observed in the current twins' sample, with Cronbach's $\alpha$ coefficients ranging from 0.77 to 0.86 (data not shown). In the majority of cases, the CEBQ at the 10-year follow-up was answered by the mother of the children $(92.6 \%)$.

At each follow-up, participants were weighed, by trained researchers, in underwear and without shoes, using a digital scale and the measure was recorded to the nearest $0.1 \mathrm{~kg}$. Height was also measured without shoes, using a fixed stadiometer to the nearest $0.1 \mathrm{~cm}$. Children's BMI was calculated and cutoff points for the sex- and age specific BMI $z$-scores were created. Weight status was then defined as 'underweight' for $z$-scores below -2 standard deviations (SD), 'normal weight' for $z$-scores $\geq-2 \mathrm{SD}$ and $\leq 1 \mathrm{SD}$, 'overweight' for $z$-scores $>1$ and $\leq 2 \mathrm{SD}$ and 'obesity' for $z$-scores above 2SD, according to the World Health Organization (WHO) child growth references [26].

Maternal demographic characteristics, such as age, education, marital status, pre-pregnancy weight and height, gestational age, and household monthly income were obtained through face-to-face interviews conducted by trained researchers. Mother's weight status was classified as follows: $\mathrm{BMI}<18.5 \mathrm{~kg} / \mathrm{m}^{2}$ for 'underweight', between $\geq 18.5$ and $<25 \mathrm{~kg} / \mathrm{m}^{2}$ for 'normal weight', between $\geq 25$ and $<30 \mathrm{~kg} / \mathrm{m}^{2}$ for 'overweight' and $\geq 30 \mathrm{~kg} / \mathrm{m}^{2}$ for 'obesity', according to WHO cut-offs [27]. Child birth weight was recorded in grams after birth and were retrieved from medical records by trained researchers. Birth weight categories were defined as $<1000 \mathrm{~g}$ as 'extremely low', between 1000 and $1499 \mathrm{~g}$ as 'very low', between 1500 and $2499 \mathrm{~g}$ as 'low' and $\geq 2500 \mathrm{~g}$ as 'normal', according to WHO thresholds [28], and was used for descriptive purposes only.

\section{Statistical analysis}

Continuous variables were expressed as mean and standard deviations (M(SD)) for symmetric distributed variables, or median and interquartile ranges $(\mathrm{Md}(\mathrm{IQR})$ ) for non-symmetric distributed variables. Distribution of variables was evaluated for each continuous variable using Kolmogorov-Smirnov test and graphically, through $Q-Q$ plots. Counts and percentages $(n(\%))$ were described for categorical variables.

To explore genetic and environmental contributions on variations of the CEBQ subscales, intra-class correlation coefficients (ICC) calculations (two-way mixed-single measure) and the twin method [29] were used. First, to assess the resemblance between identical and fraternal twins, ICCs for each CEBQ subscale were calculated. Greater similarities (i.e., greater ICCs) between MZ twins, compared to DZ twins, indicate a greater genetic contribution to the variation of the trait, because the only difference between these two types of twins is that the identical twins (MZ) are twice as similar genetically [17].

The twin method consists of a formal comparison between the resemblance between identical (MZ) and fraternal twins (DZ) for some traits of interest. MZ twins are genetically identical $(100 \%)$ and, if reared together, share the same environment, and DZ twins share half of their genes (50\%) and, if reared together, also share the same environment [29]. The maximum likelihood structural equation modeling (MLSEM) was conducted aiming to estimate the genetic and environmental variances in the measured eating 
behaviors from the twin method. The genetic component comprises additive genetic influences $(A)$. The environmental component compromises common or shared environmental influences $(C)$, which represent factors common to both twins (e.g., socioeconomic status) and child-specific or non-shared environmental factors $(E)$, which refer to factors in the environment that make members of the twin pair different (e.g., an illness in only one twin) [30]. Parameter estimates, their respective 95\% confidence intervals (CI), as well as models' goodness-of-fit statistics were evaluated and described. Although we tested the full ACE model for each appetitive trait, considering the small sample size and the fit index, we only reported bivariate estimates of $A, C$ and $E$ (i.e., AC, AE and CE). These models were then compared according to the following fit indexes: Bayesian information criterion (BIC) value, log likelihood ratio (-LL), Chisquared value $\left(\chi^{2}\right)$ and $p$ value. Only models with the best fit, i.e., that explained the observed variance and covariance with the fewest parameters for each appetitive trait, were described (models with the lowest BIC value, smallest $\chi^{2}$ and $p>0.05$ ) [31]. Details of the remaining fitted models are described in a Supplementary Table (Supplementary Table 1).

Descriptive statistics and ICCs were performed in SPSS (IBM Corp. Released 2017. IBM SPSS Statistics for Windows, Version 25.0. Armonk, NY: IBM Corp.) and the MLSEM was performed in R 3.0.1 using the structural equation modeling package NlsyLinks [32].

\section{Results}

Demographic and anthropometric characteristics of the 172 mother-child dyads are described in Table 1. Sixty-five percent of children were DZ twins, and nearly $63 \%$ were born with low weight $(<2500 \mathrm{~g})$. At 10 years, a third of twins were classified as having overweight or obesity (30.2\%).

CEBQ subscales are described and ICCs for MZ and DZ twin pairs are shown in Table 2. Means of appetitive traits did not differ between MZ and DZ twins. For all appetitive traits, ICCs for MZ twins were significant and higher, compared to DZ twins. However, 95\% CI overlapped for all four food approach behaviors (i.e., enjoyment of food, food responsiveness, desire to drink and emotional overeating) and for emotional undereating. For the latter, a significantly higher ICC was observed among DZ twins (ICC: 0.76; 95\% CI $0.62 ; 0.85)$, suggesting that this trait has strong environmental factors explaining its variability. ICCs were significantly higher in MZ twins, compared to DZ twins, with nonoverlapping $95 \% \mathrm{CI}$, for satiety responsiveness, slowness in eating and food fussiness.

Genetic and environmental parameter estimates and goodness-of-fit statistics for the best-fitted model, for each
Table 1 Characteristics of the Generation XXI twin sample $(n=172$ or 86 twin pairs)

\begin{tabular}{|c|c|}
\hline \multicolumn{2}{|l|}{ Mother } \\
\hline Age at baseline (years)—Md (IQR) & $31.0(5.0)$ \\
\hline Education at baseline (years) - $\mathrm{Md}(\mathrm{IQR})$ & $12.0(9.0)$ \\
\hline \multicolumn{2}{|l|}{ Household monthly income $(€)-n(\%)$} \\
\hline$\leq 1000$ & $52(33.3)$ \\
\hline $1001-2000$ & $59(37.8)$ \\
\hline$>2000$ & $45(28.8)$ \\
\hline \multicolumn{2}{|l|}{ Marital status- $n(\%)$} \\
\hline Married/in a relationship & $168(97.7)$ \\
\hline Single/separated/divorced/widowed & $4(2.3)$ \\
\hline BMI at baseline $\left(\mathrm{kg} / \mathrm{m}^{2}\right)-\mathrm{Md}(\mathrm{IQR})$ & $23.1(5.0)$ \\
\hline \multicolumn{2}{|l|}{ Weight status at baseline ${ }^{\mathrm{a}}-n(\%)$} \\
\hline Underweight $\left(<18.5 \mathrm{~kg} / \mathrm{m}^{2}\right)$ & $8(4.8)$ \\
\hline Normal weight $\left(18.5-24.9 \mathrm{~kg} / \mathrm{m}^{2}\right)$ & $111(66.1)$ \\
\hline Overweight $\left(25.0-29.9 \mathrm{~kg} / \mathrm{m}^{2}\right)$ & $33(19.6)$ \\
\hline Obesity $\left(\geq 30.0 \mathrm{~kg} / \mathrm{m}^{2}\right)$ & $16(9.5)$ \\
\hline \multicolumn{2}{|l|}{ Child } \\
\hline \multicolumn{2}{|l|}{$\operatorname{Sex}-n(\%)$} \\
\hline Male & $89(51.7)$ \\
\hline Female & $83(48.3)$ \\
\hline \multicolumn{2}{|l|}{ Zygosity—n(\%) } \\
\hline $\mathrm{MZ}$ & $60(34.9)$ \\
\hline $\mathrm{DZ}$ & $112(65.1)$ \\
\hline Gestational age (weeks)—Md (IQR) & $36.0(3.0)$ \\
\hline Birth weight (g)-Md (IQR) & $2302.5(754)$ \\
\hline \multicolumn{2}{|l|}{ Birth weight ${ }^{\mathrm{b}}-n(\%)$} \\
\hline Extremely low $(<1000 \mathrm{~g})$ & $4(2.3)$ \\
\hline Very low (1000-1499 g) & $22(12.8)$ \\
\hline Low (1500-2499 g) & $82(47.7)$ \\
\hline Normal ( $\geq 2500 \mathrm{~g})$ & $64(37.2)$ \\
\hline Age (years)—Md (IQR) & $10.0(0.0)$ \\
\hline BMI z-score-M (SD) & $0.2(1.3)$ \\
\hline \multicolumn{2}{|l|}{ Weight status ${ }^{\mathrm{c}}-n(\%)$} \\
\hline Underweight $(<-2 \mathrm{SD})$ & $7(4.0)$ \\
\hline Normal weight $(\geq-2 \mathrm{SD}$ and $\leq 1 \mathrm{SD})$ & $113(65.7)$ \\
\hline Overweight $(>1$ and $\leq 2 \mathrm{SD})$ & $33(19.2)$ \\
\hline Obesity $(>2 \mathrm{SD})$ & $19(11.0)$ \\
\hline
\end{tabular}

$M$ mean, $S D$ standard deviations, $M d$ median, $I Q R$ interquartile range, $M Z$ monozygotic twins, $D Z$ dizygotic twins, $B M I$ body mass index

${ }^{a}$ Mother weight status categories were defined according to the WHO cut-offs [27]

${ }^{\mathrm{b}}$ Birth weight categories were defined according to the WHO cut-offs [28]

${ }^{\mathrm{c}}$ Child weight status categories were defined according to the WHO child growth references [26]

appetitive trait at 10 years, are described in Table 3. For all appetitive traits, with exception of emotional undereating (CEBQ-EUE), the best model was estimated by additive genetic $(A)$ and non-shared environmental $(E)$ effects. 
Table 2 Appetitive traits descriptive, intra-class correlation coefficients (ICCs) and respective confidence intervals (95\% CI), according to twin's zygosity, at 10 years of age ( $n=86$ twin pairs)

\begin{tabular}{|c|c|c|}
\hline \multirow{3}{*}{$\begin{array}{l}\text { Child appetitive traits } \\
\text { (CEBQ) }\end{array}$} & \multicolumn{2}{|l|}{ Zygosity } \\
\hline & MZ & $\mathrm{DZ}$ \\
\hline & $\begin{array}{l}\text { ICC }(95 \% \text { CI }) \\
\text { M (SD) }\end{array}$ & \\
\hline \multirow[t]{2}{*}{ Enjoyment of food } & $0.81(0.62 ; 0.90)$ & $0.56(0.35 ; 0.72)$ \\
\hline & $3.10(0.72)$ & $3.16(0.77)$ \\
\hline \multirow[t]{2}{*}{ Food responsiveness } & $0.68(0.41 ; 0.83)$ & $0.47(0.24 ; 0.65)$ \\
\hline & $2.12(0.68)$ & $2.05(0.73)$ \\
\hline \multirow[t]{2}{*}{ Desire to drink } & $0.86(0.72 ; 0.93)$ & $0.57(0.37 ; 0.73)$ \\
\hline & $1.99(0.53)$ & $2.09(0.66)$ \\
\hline \multirow[t]{2}{*}{ Emotional overeating } & $0.88(0.75 ; 0.94)$ & $0.63(0.44 ; 0.77)$ \\
\hline & $1.89(0.62)$ & $1.84(0.62)$ \\
\hline \multirow[t]{2}{*}{ Satiety responsiveness } & $0.88(0.77 ; 0.94)$ & $0.37(0.13 ; 0.58)$ \\
\hline & $2.61(0.63)$ & $2.56(0.65)$ \\
\hline \multirow[t]{2}{*}{ Slowness in eating } & $0.76(0.55 ; 0.88)$ & $0.04(-0.22 ; 0.29)$ \\
\hline & $2.68(0.90)$ & $2.76(0.89)$ \\
\hline \multirow[t]{2}{*}{ Food fussiness } & $0.71(0.48 ; 0.85)$ & $0.10(-0.16 ; 0.35)$ \\
\hline & $2.86(0.66)$ & $2.94(0.79)$ \\
\hline \multirow[t]{2}{*}{ Emotional undereating } & $0.89(0.78 ; 0.95)$ & $0.76(0.62 ; 0.85)$ \\
\hline & $2.28(0.79)$ & $2.33(0.68)$ \\
\hline
\end{tabular}

Bold values are statistically significant $(p \leq 0.05)$

$M$ means, $S D$ standard deviations, $M Z$ monozygotic twins, $D Z$ dizygotic twins, ICC intra-class correlations, $C E B Q$ Children's Eating Behavior Questionnaire
Genetic effects were stronger for enjoyment of food (82\%), desire to drink (90\%), emotional overeating (87\%) and satiety responsiveness $(88 \%)$. For emotional undereating, environmental effects seem to be more important than genetic effects (shared environment-C: $0.81 ; 95 \%$ CI $0.71 ; 0.88$ and non-shared environment-E: $0.19 ; 95 \%$ CI $0.12 ; 0.29)$.

\section{Discussion}

Several appetitive traits at 10 years showed moderate to high heritability, but they were also partially explained by the individual's unique environment (i.e., the non-shared environment). On the other hand, children's tendency to eat less in response to negative emotions seem to be determined by the shared and non-shared environments, rather than being genetically predicted.

The heritability estimates observed for the food approach behaviors are in line with previous studies [10, 11, 18]. Specifically, among Canadian children, heritability of eating too much and eating too fast in 2.5 years was estimated to be $87 \%$ and $71 \%$, respectively, and, in the 9-year-old sample, eating between meals showed $72 \%$ of genetic predisposition [18]. In the UK, food responsiveness was estimated to be $75 \%$ heritable in $8-11$ years [10], and heritability of eating rate, among 10-12 years, was estimated to be $62 \%$ [11]. These findings indicate that being reared in the same household has a relatively small effect on making twins

Table 3 Genetic and environmental effects on variations of the CEBQ subscales (best fitted models, parameter estimates and respective confidence intervals $(95 \% \mathrm{CI})$ at 10 years of age ( $n=86$ twin pairs)

\begin{tabular}{|c|c|c|c|c|c|c|c|c|c|}
\hline & Additive genetic effect $(A)$ & $\begin{array}{l}\text { Shared environ- } \\
\text { ment effect }(C)\end{array}$ & $\begin{array}{l}\text { Non-shared envi- } \\
\text { ronment effect }(E)\end{array}$ & df & $\mathrm{BIC}$ & $\chi^{2}$ & $-\mathrm{LL}$ & $\Delta-\mathrm{LL}$ & $p$ value \\
\hline \multicolumn{10}{|c|}{ Enjoyment of food } \\
\hline $\mathrm{AE}$ & $0.82(0.68 ; 0.93)$ & - & $0.18(0.07 ; 0.32)$ & 7.00 & 356.327 & 11.299 & -171.464 & 5.649 & 0.126 \\
\hline \multicolumn{10}{|c|}{ Food responsiveness } \\
\hline $\mathrm{AE}$ & $0.69(0.41 ; 0.93)$ & - & $0.31(0.07 ; 0.59)$ & 7.00 & 363.020 & 11.170 & -174.794 & 5.585 & 0.131 \\
\hline \multicolumn{10}{|c|}{ Desire to drink } \\
\hline $\mathrm{AE}$ & $0.90(0.78 ; 0.97)$ & - & $0.10(0.04 ; 0.23)$ & 7.00 & 281.631 & 7.312 & -134.100 & 3.656 & 0.397 \\
\hline \multicolumn{10}{|c|}{ Emotional overeating } \\
\hline $\mathrm{AE}$ & $0.87(0.78 ; 0.95)$ & - & $0.13(0.05 ; 0.22)$ & 7.00 & 271.734 & 8.854 & -129.134 & 4.427 & 0.263 \\
\hline \multicolumn{10}{|c|}{ Satiety responsiveness } \\
\hline $\mathrm{AE}$ & $0.88(0.77 ; 0.95)$ & - & $0.12(0.05 ; 0.23)$ & 7.00 & 304.246 & 4.310 & -145.407 & 2.155 & 0.743 \\
\hline \multicolumn{10}{|c|}{ Slowness in eating } \\
\hline $\mathrm{AE}$ & $0.69(0.19 ; 0.94)$ & - & $0.31(0.06 ; 0.81)$ & 7.00 & 448.635 & 10.394 & -217.618 & 5.197 & 0.167 \\
\hline \multicolumn{10}{|c|}{ Food fussiness } \\
\hline $\mathrm{AE}$ & $0.70(0.08 ; 0.95)$ & - & $0.30(0.05 ; 0.93)$ & 7.00 & 396.215 & 13.071 & -191.391 & 6.535 & 0.070 \\
\hline \multicolumn{10}{|c|}{ Emotional undereating } \\
\hline $\mathrm{CE}$ & - & $0.81(0.71 ; 0.88)$ & $0.19(0.12 ; 0.29)$ & 7.00 & 298.774 & 5.275 & -142.671 & 2.638 & 0.626 \\
\hline
\end{tabular}

$C E B Q$ Children's Eating Behavior Questionnaire, $A$ additive genetic component of variance, $C$ shared environmental component of variance, $E$ non-shared environmental component of variance, $d f$ degrees of freedom, BIC Bayesian information criterion, $\chi^{2}$ Chi-squared test, $-L L$ loglikelihood of data 
similar to one another for most appetitive traits in middlechildhood [10]. The found contribution of both genetic and non-shared environmental influences on children's appetitive traits corroborates with other studies in this same age-group $[10,11,18]$, indicating that siblings have unique experiences inside and outside the household and, therefore, differ in their behavioral responses to that environment (i.e., appetitive traits). There is a general trend for no shared environmental component (i.e., the 'C' estimate) in specific behaviors, such as eating rate and quantity of food eaten among preschool- and school-aged children [18] and uncontrolled eating among adults [33], with the remaining non-genetic variance being explained mostly by environmental factors that are not shared by twins (i.e., the 'E' estimate), which measure "each twin's unique experiences of the world".

A significant genetic component was also found for the food avoidant behaviors. The genetic component underlying food fussiness, for example, has been described to be $46 \%$ among 16-month-old children [14], 78\% among 3 years [15], 73\% among 9 years (assessed by a single question about the child being fussy about eating vegetables) [18] and 70\% in the current sample, which suggests that this appetitive trait seems to increase its genetic predisposition in the first years of life. In addition to the genetic effect, children's non-shared/unique environment also seemed to explain more in the variability of food fussiness, compared to the shared environment, and this corroborates with previous studies in preschool- [15] and in school-age years [18]. These findings suggest that the home environment shapes this particular trait especially in early life, being, therefore, a sensitive period to intervene. The early life home environment includes a variety of aspects, such as the availability and accessibility to healthy foods, which have shown to be associated with child greater food consumption and less food fussiness [34], as well as the use of specific parent-feeding strategies, such as repeated exposure to fruit and vegetables [35], which decreases fussy eating. In addition, parents may act as role models for a healthier food consumption and providers of a mealtime structure [36], which have shown to have positive consequences on food preferences and dietary quality, decreasing fussy eating, and should, therefore, be encouraged in early years.

Our second hypothesis was partially confirmed. We found that emotional undereating was largely explained by environmental factors (shared and non-shared), with genetic influences playing a minor role; however, emotional overeating showed an important genetic predisposition in our sample ('A': $0.87,95 \%$ CI $0.78 ; 0.95$ ). A study that analyzed data from the Gemini twin study in the UK found, besides the great effect of environmental factors on emotional undereating, that emotional overeating was also largely explained by environmental factors [17]. The main differences to our study are the English younger age-group (5 years of age) and larger sample size ( $n=1027$ twin pairs), so heritability may have increased in this appetitive trait among the older children in our study or we may have lacked in power to estimate environmental effects on emotional overeating. However, twin studies among adults have shown effects of both genetic and non-shared environmental factors on emotional overeating [37, 38], suggesting that genetic influences on this trait may also increase over time, as seen with other eating behaviors. As described in a review by Herle and colleagues [39], emotional overeating is affected by genetic and environmental cues that vary considerably throughout life. This behavior emerges in early ages, and its etiology may change when the child ages. The home environment (i.e., parental influence), for example, seems to play a major role in its development among young children, and external factors, such as peers, show a significant importance later in childhood. However, further studies are necessary to confirm this hypothesis.

A variety of environmental factors may influence child's emotional eating; however, the specific environmental cues that influence children's appetitive traits were not investigated in the present study. Four levels of environmental factors that may influence eating behaviors have been suggested by Story et al., as follows: individual factors (which include psychological and biological factors), the social environment (such as parents and peers), the physical environment (such as schools, restaurants and food availability) and the societal level in which children live in (which include, for example, cultural and social norms, marketing and advertising) [40]. The primary influence on child eating behaviors often occur at home, particularly with parents engaging in feeding practices [30] to maintain or modify child's weight and/or eating habits [41]. However, corroborating with our results (with exception to emotional undereating), others found small effects of twin's shared environment on appetitive traits [15, 18] and BMI in childhood [42]. Even though siblings experience the same food environment, are served with similar foods, see the same behaviors modeled by parents, have similar indoor and outdoor activities, and go to the same school, these results show that these factors do not make siblings more similar-which is a challenge for obesity etiological models that highlight the home environment as a root for obesity development [42].

The effect of genes underlying pediatric appetitive traits does not mean that environmental changes to improve dietary quality and/or prevent inadequate weight do not work, but rather that this control is likely to be more difficult for some children, given the combination of genetically determined appetite and the obesogenic food environment that increases opportunities to overeat [10]. This means that, as vastly described, the food environment has a great influence on eating behaviors and weight gain in childhood $[2,43$, 
44] and adolescence [40, 45], being, therefore, public health interventions highly encouraged when necessary.

\section{Strength and limits}

This study has some limitations that need to be addressed. First, a major limitation is the small sample size of twin pairs in the Generation XXI birth cohort, which may have decreased the reliability of the parameter estimates and widened and overlapped confidence intervals. A larger sample size might have allowed detecting smaller additive and environmental influences. The wide confidence intervals for the parameter estimates indicate the need for replication in larger samples. It was not possible to carry out a power analyses prior to this cohort study. However, post hoc analyses revealed the study sample of 172 children had approximately $40 \%$ power to detect a significant genetic effect with a variance component of 0.33 and a shared environment variance component of 0.1 [46]. Previous twin studies conducted in the UK used large samples of twins [13, 14, 17], which led to more precise estimations of genetic and environmental contributions on appetitive traits. A strength of ours study is that twins from an ongoing prospective cohort were studied, instead of a sample of twins specifically recruited to answer this objective, which brings several advantages from the multiple and extensive follow-up conducted across time.

Second, the parent-report nature of children's appetitive traits may have introduced measurement error due to subjectivity and social desirability bias [47]. In addition, it represents parent's perceptions and child eating behaviors outside parents' view, such as in the school environment, could be different and not described here. Another limitation is the evaluation of eating behaviors using a common source or rater (in this case, the mother responded for both twins). As described in the review by Podsakoff et al., people try to appear consistent and rational in their answers, producing relationships that would not appear in real-life settings [47]. However, the CEBQ has demonstrated good internal consistency in this population [24] and good correspondence with objective behavioral measures of children's eating [48]. In addition, a limitation of the twin method is the equal-environment assumption, which could overestimate heritability estimates. It has been discussed by others [49, 50] that the assumption of equal shared environment among MZ and DZ may not be entirely true, arguing that MZ twins experience environments that are more similar compared to DZ twins. In the comprehensive review of Felson [50], the use of equal-environment assumption in twin studies is valid in most cases; however, violations of this assumptions may also exist and increase heritability estimates. In twin studies assessing eating behaviors and attitudes, the equalenvironment assumption has shown to be reliable [51].

This is, to our knowledge, the first study among Portuguese children that assessed heritability of appetitive traits, which extend the previous findings from other populations. The findings of this study suggest that there is a significant genetic contribution for the establishment of appetitive traits among 10 years, especially for enjoyment of food ( $82 \%$ ), desire to drink (90\%), emotional overeating $(87 \%)$ and satiety responsiveness $(88 \%)$. Despite the great heritability of appetitive traits in school-age years, variability of behaviors was also explained by the unique environment, which can be addressed in public health interventions. Emotional undereating was the only trait that was not heritable, with a significant proportion of this trait being explained by both common and unique environmental factors. The recognized and complex genotype-environment interaction needs to be considered when investigating the etiology of appetitive traits. Understanding which genes are associated with appetitive traits in childhood would give a powerful insight in the biological and behavioral influences on child eating and obesity risk [30].

\section{What is already known on this subject?}

There is a complex gene-environment interplay in the development of obesity, which proposes that its genetic risk operates through inherited appetitive traits that confer individual's differential susceptibility to the food environment. Twin studies in the UK have shown substantial genetic influence on potentially obesogenic appetitive traits in children.

\section{What your study adds?}

This study expands on previous findings in a different culture and older age-group on the genetic and environmental variability in appetitive traits in a Portuguese sample of schoolage children.

Supplementary Information The online version contains supplementary material available at https://doi.org/10.1007/s40519-021-01322-1.

Acknowledgements The authors gratefully acknowledge the families enrolled in Generation XXI for their kindness, all members of the research team for their enthusiasm and perseverance and the participating hospitals and their staff for their help and support.

Author contributions SW was responsible for study concept, data analysis and interpretation; drafting of the manuscript and final approval of the version to be published. MS was responsible for data analysis; interpretation of data; critical revision of the manuscript, and final approval of the version to be published. AF was responsible for interpretation of data; critical revision of the manuscript, and final approval of the 
version to be published. AO was co-responsible for study concept; interpretation of data; critical revision of the manuscript, and final approval of the version to be published. All authors read and approved the final manuscript.

Funding Generation XXI was funded by the Health Operational Programme-Saúde XXI, Community Support Framework III and the Regional Department of Ministry of Health. This study was supported through FEDER from the Operational Programme Factors of Competitiveness-COMPETE and through national funding from the Foundation for Science and Technology-FCT (Portuguese Ministry of Education and Science) under the projects "Appetite regulation and obesity in childhood: a comprehensive approach towards understanding genetic and behavioural influences" (POCI-01-0145-FEDER-030334; PTDC/SAUEPI/30334/2017); "Appetite and adiposity-evidence for gene-environment interplay in children" (IF/01350/2015), and through Investigator Contract (IF/01350/2015-Andreia Oliveira). It had also support from the Epidemiology Research Unit (EPI-Unit: UIDB/04750/2020; POCI-01-0145-FEDER-006862) and the Calouste Gulbenkian Foundation, Portugal.

Data availability The data sets generated during and/or analysed during the current study are available from the corresponding author on reasonable request.

\section{Declarations}

Conflict of interest The authors have no conflict of interest relevant to this article to disclose.

Ethical approval Generation XXI was approved by the University of Porto Medical School/S. João Hospital Centre Ethics Committee and by the Portuguese Data Protection Authority. All the phases of the study complied with the Ethical Principles for Medical Research Involving Human Subjects expressed in the Declaration of Helsinki.

Consent to participate A written informed assent from the parents (or legal substitute) and an oral consent from the children were obtained in each evaluation.

\section{Consent for publication Not applicable.}

Open Access This article is licensed under a Creative Commons Attribution 4.0 International License, which permits use, sharing, adaptation, distribution and reproduction in any medium or format, as long as you give appropriate credit to the original author(s) and the source, provide a link to the Creative Commons licence, and indicate if changes were made. The images or other third party material in this article are included in the article's Creative Commons licence, unless indicated otherwise in a credit line to the material. If material is not included in the article's Creative Commons licence and your intended use is not permitted by statutory regulation or exceeds the permitted use, you will need to obtain permission directly from the copyright holder. To view a copy of this licence, visit http://creativecommons.org/licenses/by/4.0/.

\section{References}

1. Wood AC (2018) Gene-environment interplay in child eating behaviors: what the role of "nature" means for the effects of "nurture." Curr Nutr Rep 7:294-302. https://doi.org/10.1007/ s13668-018-0254-x
2. Schrempft S, Van Jaarsveld CHM, Fisher A et al (2018) Variation in the heritability of child body mass index by obesogenic home environment. JAMA Pediatr 172:1153-1160. https://doi.org/10. 1001/jamapediatrics.2018.1508

3. Llewellyn CH, Trzaskowski M, Plomin R, Wardle J (2014) From modeling to measurement: developmental trends in genetic influence on adiposity in childhood. Obesity 22:1756-1761. https:// doi.org/10.1002/OBY.20756

4. Min J, Chiu DT, Wang Y (2013) Variation in the heritability of body mass index based on diverse twin studies: a systematic review. Obes Rev 14:871-882. https://doi.org/10.1111/OBR. 12065

5. Llewellyn C, Wardle J (2015) Behavioral susceptibility to obesity: gene-environment interplay in the development of weight. Physiol Behav 152:494-501. https://doi.org/10.1016/j.physbeh.2015.07. 006

6. Bouchard C (2008) Gene-environment interactions in the etiology of obesity: defining the fundamentals. Obesity 16:5-10. https:// doi.org/10.1038/oby.2008.528

7. Dubois L, Ohm Kyvik K, Girard M et al (2012) Genetic and environmental contributions to weight, height, and BMI from birth to 19 years of age: an international study of over 12,000 twin pairs. PLoS One. https://doi.org/10.1371/journal.pone. 0030153

8. Silventoinen K, Jelenkovic A, Sund R et al (2016) Genetic and environmental effects on body mass index from infancy to the onset of adulthood: an individual-based pooled analysis of 45 twin cohorts participating in the COllaborative project of Development of Anthropometrical measures in Twins (CODATwins). Am J Clin Nutr 104:371-379. https://doi.org/10.3945/ajcn.116.130252

9. Carnell S, Wardle J (2008) Appetite and adiposity in children: evidence for a behavioral susceptibility theory of obesity. Am J Clin Nutr 88:22-29. https://doi.org/10.1093/ajcn/88.1.22

10. Carnell S, Haworth CMA, Plomin R, Wardle J (2008) Genetic influence on appetite in children. Int J Obes 32:1468-1473. https://doi.org/10.1038/ijo.2008.127

11. Llewellyn CH, Van Jaarsveld CHM, Boniface D et al (2008) Eating rate is a heritable phenotype related to weight in children. Am J Clin Nutr 88:1560-1566. https://doi.org/10.3945/ajcn.2008. 26175

12. Fisher JO, Cai G, Jaramillo SJ et al (2007) Heritability of hyperphagic eating behavior and appetite-related hormones among hispanic children. Obesity 15:1484-1495. https://doi.org/10.1038/ oby. 2007.177

13. Llewellyn CH, Van Jaarsveld CHM, Plomin R et al (2012) Inherited behavioral susceptibility to adiposity in infancy: a multivariate genetic analysis of appetite and weight in the Gemini birth cohort. Am J Clin Nutr 95:633-639. https://doi.org/10.3945/ajcn. 111.023671

14. Smith AD, Herle M, Fildes A et al (2017) Food fussiness and food neophobia share a common etiology in early childhood. J Child Psychol Psychiatry Allied Discip 58:189-196. https://doi.org/10. 1111/jcpp. 12647

15. Fildes A, Van Jaarsveld CHM, Cooke L et al (2016) Common genetic architecture underlying young children's food fussiness and liking for vegetables and fruit. Am J Clin Nutr 103:10991104. https://doi.org/10.3945/ajcn.115.122945

16. Faith MS, Heo M, Keller KL, Pietrobelli A (2013) Child food neophobia is heritable, associated with less compliant eating, and moderates familial resemblance for BMI. Obesity 21:1650-1655. https://doi.org/10.1002/oby.20369

17. Herle M, Fildes A, Steinsbekk S et al (2017) Emotional over- and under-eating in early childhood are learned not inherited. Sci Rep 7:1-9. https://doi.org/10.1038/s41598-017-09519-0

18. Dubois L, Diasparra M, Bédard B et al (2013) Genetic and environmental influences on eating behaviors in 2.5- and 9-year-old 
children: a longitudinal twin study. Int J Behav Nutr Phys Act 10:1-12. https://doi.org/10.1186/1479-5868-10-134

19. Vesnaver E, Keller HH (2011) Social influences and eating behavior in later life: a review. J Nutr Gerontol Geriatr 30:2-23. https:// doi.org/10.1080/01639366.2011.545038

20. Alves E, Correia S, Barros H, Azevedo A (2012) Prevalence of self-reported cardiovascular risk factors in Portuguese women: a survey after delivery. Int J Public Health 57:837-847. https://doi. org/10.1007/s00038-012-0340-6

21. Larsen PS, Kamper-Jørgensen M, Adamson A et al (2013) Pregnancy and birth cohort resources in Europe: a large opportunity for aetiological child health research. Paediatr Perinat Epidemiol 27:393-414. https://doi.org/10.1111/ppe.12060

22. Peeters H, Van Gestel S, Vlietinck R et al (1998) Validation of a telephone zygosity questionnaire in twins of known zygosity. Behav Genet 28:159-163. https://doi.org/10.1023/A:1021416112 215

23. Wardle J, Guthrie CA, Sanderson S, Rapoport L (2001) Development of the children's eating behaviour questionnaire. J Child Psychol Psychiatry 42:963-970. https://doi.org/10.1111/1469-7610. 00792

24. Albuquerque G, Severo M, Oliveira A (2017) Early life characteristics associated with appetite-related eating behaviors in 7-yearold children. J Pediatr 180:38-46. https://doi.org/10.1016/j.jpeds. 2016.09.011

25. Costa A, Severo M, Vilela S et al (2020) Bidirectional relationships between appetitive behaviours and body mass index in childhood: a cross-lagged analysis in the Generation XXI birth cohort. Eur J Nutr. https://doi.org/10.1007/s00394-020-02238-9

26. de Onis M, Onyango AW, Borghi E et al (2007) Development of a WHO growth reference for school-aged children and adolescents. Bull World Health Organ 85:660-667

27. World Health Organization (WHO) (1999) Obesity: preventing and managing the global epidemic. https://apps.who.int/iris/handle/10665/42330. Accessed 15 Feb 2021

28. World Health Organization (WHO) (2011) International statistical classification of diseases and related health problems. 10th revision. https://www.who.int/standards/classifications/classifica tion-of-diseases. Accessed 15 Feb 2021

29. Mayo O (2009) Early research on human genetics using the twin method: who really invented the method? Twin Res Hum Genet 12:237-245. https://doi.org/10.1375/twin.12.3.237

30. Wood AC (2018) Appetitive traits: genetic contributions to pediatric eating behaviors. In: Lumeng JC, Fisher JO (eds) Pediatric food preferences and eating behaviors. Elsevier Inc., Amsterdam, pp 127-146

31. Posada D, Buckley TR (2004) Model selection and model averaging in phylogenetics: advantages of Akaike information criterion and bayesian approaches over likelihood ratio tests. Syst Biol 53:793-808. https://doi.org/10.1080/10635150490522304

32. Beasley W, Rodgers J, Bard D et al (2016) Utilities and kinship information for research with the NLSY. https://rdrr.io/rforge/ NlsyLinks/. Accessed 27 Jan 2021

33. Vainik U, García-García I, Dagher A (2019) Uncontrolled eating: a unifying heritable trait linked with obesity, overeating, personality and the brain. Eur J Neurosci 50:2430-2445. https://doi.org/ 10.1111/ejn. 14352

34. Harris HA, Staton S, Morawska A et al (2019) A comparison of maternal feeding responses to child fussy eating in low-income food secure and food insecure households. Appetite 137:259-266. https://doi.org/10.1016/j.appet.2019.03.005

35. Mallan KM, Fildes A, Magarey AM, Daniels LA (2016) The relationship between number of fruits, vegetables, and noncore foods tried at age 14 months and food preferences, dietary intake patterns, fussy eating behavior, and weight status at age 3.7 years. J Acad Nutr Diet 116:630-637. https://doi.org/10.1016/j.jand.2015. 06.006
36. Powell F, Farrow C, Meyer C, Haycraft E (2017) The importance of mealtime structure for reducing child food fussiness. Matern Child Nutr 13:e12296. https://doi.org/10.1111/mcn.12296

37. Tholin S, Rasmussen F, Tynelius P, Karlsson J (2005) Genetic and environmental influences on eating behavior: the Swedish Young Male Twins Study. Am J Clin Nutr 81:564-569. https://doi.org/ 10.1093/ajcn/81.3.564

38. Keskitalo K, Tuorila H, Spector TD et al (2008) The Three-Factor Eating Questionnaire, body mass index, and responses to sweet and salty fatty foods: a twin study of genetic and environmental associations. Am J Clin Nutr 88:263-271. https://doi.org/10.1093/ ajcn/88.2.263

39. Herle M, Fildes A, Rijsdijk F et al (2018) The home environment shapes emotional eating. Child Dev 89:1423-1434. https://doi. org/10.1111/cdev.12799

40. Story M, Neumark-Sztainer D, French S (2002) Individual and environmental influences on adolescent eating behaviors. J Am Diet Assoc 102:S40-S51. https://doi.org/10.1016/S0002-8223(02) 90421-9

41. Warkentin S, Mais LA, Latorre MRDO et al (2018) Relationships between parent feeding behaviors and parent and child characteristics in Brazilian preschoolers: a cross-sectional study. BMC Public Health. https://doi.org/10.1186/s12889-018-5593-4

42. Wardle J, Carnell S, Haworth CM, Plomin R (2008) Evidence for a strong genetic influence on childhood adiposity despite the force of the obesogenic environment. Am J Clin Nutr 87:398-404. https://doi.org/10.1093/ajcn/87.2.398

43. Yee AZH, Lwin MO, Ho SS (2017) The influence of parental practices on child promotive and preventive food consumption behaviors: a systematic review and meta-analysis. Int J Behav Nutr Phys Act 14:1-14. https://doi.org/10.1186/s12966-017-0501-3

44. Wood AC, Blissett JM, Brunstrom JM et al (2020) Caregiver influences on eating behaviors in young children: a scientific statement from the American Heart Association. J Am Heart Assoc 9:e014520. https://doi.org/10.1161/JAHA.119.014520

45. Christiansen KMH, Qureshi F, Schaible A et al (2013) Environmental factors that impact the eating behaviors of low-income African American adolescents in Baltimore City. J Nutr Educ Behav 45:652-660. https://doi.org/10.1016/j.jneb.2013.05.009

46. Verhulst B (2017) A power calculator for the classical twin design. Behav Genet 47:255-261. https://doi.org/10.1007/ s10519-016-9828-9

47. Podsakoff PM, MacKenzie SB, Lee JY, Podsakoff NP (2003) Common method biases in behavioral research: a critical review of the literature and recommended remedies. J Appl Psychol 88:879-903. https://doi.org/10.1037/0021-9010.88.5.879

48. Carnell S, Wardle J (2007) Measuring behavioural susceptibility to obesity: validation of the child eating behaviour questionnaire. Appetite 48:104-113. https://doi.org/10.1016/j.appet.2006.07.075

49. Hettema JM, Neale MC, Kendler KS (1995) Physical similarity and the equal-environment assumption in twin studies of psychiatric disorders. Behav Genet 25:327-335. https://doi.org/10.1007/ BF02197281

50. Felson J (2014) What can we learn from twin studies? A comprehensive evaluation of the equal environments assumption. Soc Sci Res 43:184-199. https://doi.org/10.1016/j.ssresearch.2013.10.004

51. Klump KL, Holly A, Iacono WG et al (2000) Physical similarity and twin resemblance for eating attitudes and behaviors: a test of the equal environments assumption. Behav Genet 30:51-58. https://doi.org/10.1023/A:1002038610763

Publisher's Note Springer Nature remains neutral with regard to jurisdictional claims in published maps and institutional affiliations. 